\title{
PENGGUNAAN STRATEGI KWL DALAM MODEL SQ4R TERHADAP HASIL BELAJAR SISWA MATERI PELESTARIAN LINGKUNGAN
}

\author{
Arlian Firda ${ }^{1)}$ Siti Fatmawati ${ }^{2)}$ \\ 1) ,2) Pendidikan Bilogi FKIP Universitas Lancang Kuning \\ Email $^{1)}$ : arlianfirda@unilak.ac.id \\ Email $^{2)}$ : fatmawatis022@gmail.com
}

\begin{abstract}
ABSTRAK : Masalah dalam penelitian ini adalah saat pembelajaran pelestarian lingkungan siswa kurang minat membaca, siswa kurang aktif dalam proses belajar, kurang tepatnya guru menggunakan strategi dan model pembelajaran hingga rendahnya hasil belajar siswa. Penelitian ini bertujuan untuk mengetahui pengaruh strategi KWL dalam Model SQ4R Terhadap Hasil Belajar Siswa Materi Pelestarian Lingkungan Kelas X SMAN16. Penelitian ini dilaksanakan pada semester genap bulan April 2018. Penelitian ini menggunakan desain pretest - posttest Control Group Design. Sampel penelitian ini adalah kelas X.1 dan X.2 dengan jumlah masingmasing 37 siswa yang diambil secara keseluruhan. Pengumpulan data dilakukan melalui pretest, posttest dan lembar observasi siswa dan guru. Analisis data dilakukan dengan uji normalitas, uji homogenitas dan uji-t. Rerata N-Gain pada kelas eksperimen adalah 0,57 termasuk kategori sedang. Rerata N-Gain pada kelas kontrol adalah 0,34 temasuk kategori sedang. Berdasarkan hasil N-Gain maka diperoleh data yang berbeda signifikan. Dengan demikian dapat disimpulkan bahwa strategi KWL dalam model SQ4R berpengaruh terhadap hasil belajar siswa materi Pelestarian Lingkungan kelas X SMAN16.
\end{abstract}

Kata Kunci : Strategi KWL, SQ4R, hasil belajar siswa, pelestarian lingkungan

ABSTRACT : The problem in this study is that when environmental preservation learning students lack interest in reading, students are less active in the learning process, the teacher is less precise in using strategies and learning models to the low student learning outcomes. This study aims to determine the effect of the Know-Want-Learn strategy in the SQ4R learning model on student biology learning outcomes in environmental preservation material in class $X$ Pekanbaru 16 High School. This research was conducted in the even semester in April 2018. This study used the design of the pretest - posttest Control Group Design. The sample of this study was classes X.1 and X.2 with 37 students taken as a whole. Data collection was done through pretest, posttest and observation sheets of students and teachers. Data analysis was performed by normality test, homogeneity test and t-test. The mean $N$-Gain in the experimental class is 0.57 including the medium category. The mean N-Gain in the control class was 0.34 including the medium category. Based on the results of $N$-Gain, the data obtained were significantly different. Thus it can be concluded that the KWL strategy in the SQ4R model has an effect on the learning outcomes of students of class X Environmental Preservation of Senior High Schooll6.

Keywords: KWL Strategy, SQ4R, student learning achievement, environmental preservation 


\section{PENDAHULUAN}

Pendidikan merupakan salah satu faktor yang dominan bagi kehidupan manusia. Tanpa adanya pendidikan suatu negara atau bangsa tidak akan maju. Pada saat ini berbagai konsep dan wawasan tentang pendidikan sekolah telah muncul dan berkembang seiring dengan pesatnya perkembangan ilmu pengetahuan dan teknologi (Jatmiko, 2017).

Belajar merupakan suatu proses, suatu kegiatan yang berkesinambungan berlangsung hingga seumur hidup secara formal maupun non formal dan bukan suatu hasil atau tujuan. Belajar bukan hanya mengingat, akan tetapi lebih luas dari pada itu, yakni mengalami. Hasil belajar itu bukan suatu penguasaan hasil latihan, melainkan perubahan kelakuan (Hamalik, 2010).

Hasil belajar adalah kemampuankemampuan yang dimiliki siswa setelah ia menerima pengalaman belajarnya. Penilaian yang dilakukan untuk mengukur hasil belajar meliputi penilaian pada ketiga bagian, yaitu kognitif, afektif dan psikimotorik. Aspek kognitif terdiri dari enam bagian, yaitu pengetahuan, pemahaman, penerapan, analisis, sintesis, dan evaluasi. Aspek afektif terdiri dari lima bagian yaitu penerimaan, penanggapan, penilaian, pengorganisasian dan karakterisasi. Aspek psikomotorik terdiri dari lima bagian, yaitu persepsi, kesiapan, meniru, menyesuaikan dan menciptakan (Sudjana, 2010).

Penelitian ini bertujuan untuk mengetahui pengaruh strategi KWL dalam model SQ4R terhadap hasil belajar siswa materi Pelestarian Lingkungan di Kelas X SMAN 16

\section{METODE PENELITIAN}

Metode dalam penelitian ini menggunakan metode kuasi eksperimen (quasi eksperimental designs). Populasi pada penelitian ini berjumlah 151 siswa yang terdiri dari 4 kelas dan sampel terdiri dari 2 kelas yaitu kelas kontrol dan kelas eksperimen, dengan teknik simple random sampling pada sampel kelas X.1 (kelas eksperimen) dan X.2 (kelas kontrol). Pada kelas kontrol siswanya berjumlah 37 orang, dan pada kelas eksperimen berjumlah 37 orang.

Parameter dalam penelitian ini adalah hasil belajar yang di ukur dengan menggunakan soal test sebanyak 30 soal. Aktivitas mahasiswa di ukur digunakan lembar observasi aktivitas mahasiswa. Aktivitas pendidik di ukur menggunakan lembar observasi aktivitas pendidik. 


\section{HASIL DAN PEMBAHASAN}

\section{A. Hasil Penelitian}

\section{a. Analisi Data N-Gain}

Berdasarkan hasil penelitian yang diperoleh rekapitulasi data N-Gain kelas kontrol dan kelas eksperimen sebagai berikut :

Tabel 20 : Rekapitulasi Data N-Gain pada kelas Eksperimen dan Kontrol

\begin{tabular}{|c|c|c|c|c|c|c|}
\hline No & Kelas & $\mathbf{n}$ & \multicolumn{3}{|c|}{ N-Gain } & Rerata \\
\cline { 4 - 6 } & $\begin{array}{c}\text { Nilai } \\
\text { Ideal }\end{array}$ & $\begin{array}{c}\text { Nilai } \\
\text { Min }\end{array}$ & $\begin{array}{c}\text { Nilai } \\
\text { Max }\end{array}$ & \\
\hline 1 & $\begin{array}{c}\text { Eksperi } \\
\text { men }\end{array}$ & 1,00 & 0,29 & 0,87 & 0,57 \\
\hline 2 & Kontrol & 37 & 1,00 & 0,08 & 0,88 & 0,34 \\
\hline
\end{tabular}

Pada Tabel 20 nilai N-Gain minimum kelas eksperimen sebesar 0,29 sedangkan kelas kontrol sebesar 0,08. Hasil maksimum kelas eksperimen sebesar 0,87 sedangkan kelas kontrol sebesar 0,88. Rerata kelas eksperimen sebesar 0,57 sedangkan kelas kontrol sebesar 0,34 .

Perbandingan data rerata N-Gain pada kelas kontrol dan kelas eksperimen dapat

dilihat pada diagram batang berikut ini:

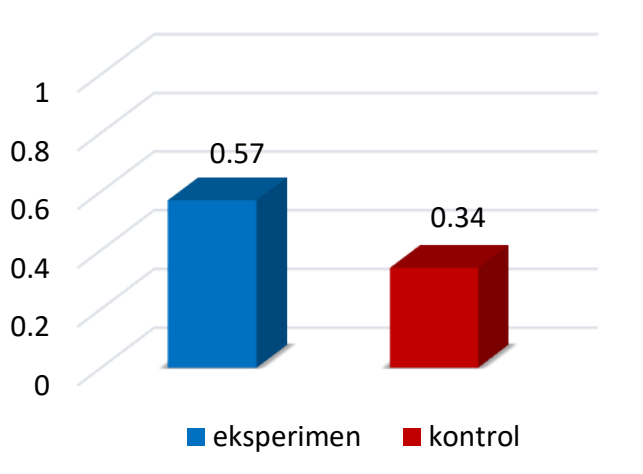

Gambar 6 : Diagram Batang Perbandingan N-Gain pada Kelas Eksperimen dan Kelas Kontrol

Berdasarkan diagram batang pada Gambar 3 dapat dilihat rerata N-Gain kelas eksperimen sebesar 0,57dengan kategori sedang dan rerata $\mathrm{N}$-Gain kelas kontrol sebesar 0,34 dengan kategori sedang. Pada kelas kontrol rerata $N$-Gain lebih rendah dari kelas eksperimen, ini menunjukkan bahwa nilai siswa kelas eksperimen lebih tinggi daripada kelas eksperimen.

Berikut ini merupakan perbandingan data N-Gain per siswa pada kelas eksperimen dan kelas kontrol yang digambarkan dengan diagram garis berikut ini:

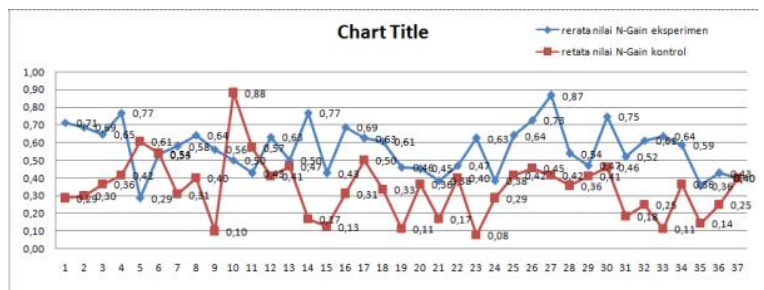

Gambar 7 : Diagram Garis N-Gain Per siswa Pada Kelas Eksperimen dan Kontrol 
Data N-Gain kelas eksperimen dan kelas kontrol yang telah didapat kemudian dianalisis dengan melakukan uji normalitas, uji homogenitas, dan uji hipotesis komparatif. Jika data berdistribusi normal dan mempunyai varian homogen maka uji yang digunakan statistik parametrik yaitu dengan uji-t, tetapi apabila data tidak berdistribusi normal dan homogen maka digunakan statistic non parametrik salah satunya dengan menggunakan uji U MannWhitney.

Untuk menguji normalitas data harus dilakukan uji normalitas,yang merupakan syarat untuk menentukan uji- $t$ menggunakan statistic parametrik dannon parametrik. $\mathrm{Uji}$ normalitas distribusi data digunakan Kolmogorof-Simirnov (KS).Data uji normalitas N-Gain pada kelas eksperimen dan kelas kontrol tertera pada tabel berikut.

Tabel 21 : Hasil Uji Normalitas N-Gain

\begin{tabular}{|c|c|c|c|c|c|}
\hline \multirow{4}{*}{$\begin{array}{c}\text { Jeni } \\
\mathbf{s}\end{array}$} & \multirow{4}{*}{ Kelas } & \multicolumn{4}{|c|}{ Uji Normalitas N-Gain } \\
\hline & & Asym & & & \\
\hline & & $\begin{array}{l}p . \\
\text { Sig }\end{array}$ & & Keputusa & Keteran \\
\hline & & $\begin{array}{c}(2- \\
\text { taile } \\
\text { d) }\end{array}$ & $\alpha$ & $\mathbf{n}$ & gan \\
\hline \multirow{2}{*}{\multicolumn{2}{|c|}{$\begin{array}{l}\text { N- Eksperin } \\
G a \text { en }\end{array}$}} & 0,200 & 0,05 & Terima $\mathrm{H}_{0}$ & Normal \\
\hline & & & & & \\
\hline in & Kontrol & 0,200 & 0,05 & Terima $\mathrm{H}_{0}$ & Normal \\
\hline
\end{tabular}

Berdasarkan Tabel 21 dapat dilihat hasil uji normalitas N-Gain pada kelas eksperimen dan kelas kontrol dengan taraf signifikan $(\alpha)$ 0,05diperoleh nilai Asymp. Sig (2-tailed) untuk kelas eksperimen sebesar 0,200>0,05 dan nilai Asymp. Sig (2-tailed )untuk kelas kontrol sebesar 0,200>0,05 sehingga pada masing-masing kelas diperoleh keputusan yang artinya data berasal dari populasi berdistribusi normal.

Selanjutnya dilakukan uji homogenitas data N-gain. Hasil uji homogenitas data NGain kelas eksperimen dan kelas kontrol dapat dilihat pada Tabel 22 di bawah ini:

Tabel 22 : Hasil Uji Homogenitas dataN-

\begin{tabular}{|c|c|c|c|c|}
\hline $\begin{array}{r}\text { Jenis } \\
\text { data }\end{array}$ & $\begin{array}{c}\text { Based on } \\
\text { trimmed } \\
\text { mean }\end{array}$ & $\boldsymbol{\alpha}$ & $\begin{array}{c}\text { Keputu } \\
\text { san }\end{array}$ & $\begin{array}{c}\text { Keter } \\
\text { anga } \\
\text { n }\end{array}$ \\
\hline $\mathrm{N}-$ & 0,514 & 0,05 & $\begin{array}{c}\text { Terima } \\
\mathrm{H}_{0}\end{array}$ & $\begin{array}{c}\text { Homog } \\
\text { en }\end{array}$ \\
\hline
\end{tabular}

Berdasarkan Tabel 22 dapat dilihat hasil uji homogenitas nilai Based on trimmed meanpada tabel Levene test 0,514 > 0,05 dengan taraf signifikan $(\alpha) 0,05$ keputusan yang diperoleh adalah terima $\mathrm{H}_{0}$. Maka artinya data N-Gain kelas eksperimen dan kelas kontrol berasal dari varian yang homogen.

Setelah data N-Gain diketahui berdistribusi normal dan homogen, maka diambil keputusan untuk melakukan uji hipotesis komparatif untuk mengetahui dataN-Gain berbeda antara kelas eksperimen dan kelas kontrol dengan menggunakan uji- $t$ Independen 2 Sampel. 
Hasil Uji-t data N-Gain dapat dilihat pada Tabel 23 berikut:

Tabel 23 : Hasil Uji-t N-Gain

\begin{tabular}{|l|l|l|l|l|}
\hline $\begin{array}{c}\text { Jenis } \\
\text { data }\end{array}$ & $\begin{array}{l}\text { Sig (2- } \\
\text { tailed })\end{array}$ & $\boldsymbol{\alpha}$ & Keputusan & Keterangan \\
\hline $\begin{array}{c}\text { N- } \\
\text { Gain }\end{array}$ & 0,000 & 0,05 & Tolak $\mathrm{H}_{0}$ & $\begin{array}{l}\text { Berbeda } \\
\text { signifikan }\end{array}$ \\
\hline
\end{tabular}

Berdasarkan Tabel 23 diperoleh nilai

Sig. (2-tailed) untuk data N-gain pada kelas eksperimen dan kelas kontrol adalah 0,000 < 0,05 dengan keputusan tolakH $\mathrm{H}_{0}$ yang artinya terdapat perbedaan antara N-Gain kelas kontrol dan kelas eksperimen. Terjadinya peningkatan hasil N-Gain menunjukkan terjadinya peningkatan hasil belajar pada materi pelestarian lingkungan. Nilai N-Gain kelas eksperimen yang menggunakan strategi Know-Want-Learn (KWL) dalam model pembelajaran SQ4R lebih tinggi dibandingkan dengan kelas kontrol yang menggunakan pembelajaran konvensional.

\section{b. Aktivitas Guru dan Siswa}

Berikut ini merupakan hasil observasi aktivitas guru kelas kontrol pertemuan I dan pertemuan II dapat dilihat pada Tabel 24.

Tabel 24 : Aktivitas Guru Kelas Eksperimen dan Kelas Kontrol

\begin{tabular}{|c|c|c|c|}
\hline Kelas & $\begin{array}{c}\text { Pertemuar } \\
\text { I (\%) }\end{array}$ & $\begin{array}{c}\text { Pertemuan } \\
\text { II (\%) }\end{array}$ & $\begin{array}{c}\text { Rerata } \\
(\mathbf{\%})\end{array}$ \\
\hline Eksperimen & 100.00 & 100.00 & 100.00 \\
\hline Kontrol & 100.00 & 100.00 & 100.00 \\
\hline
\end{tabular}

Berdasarkan Tabel 24 diatas, diketahui bahwa aktivitas guru selama kegiatan belajar mengajar dengan rerata $100 \%$. Hal ini karena guru sudah melaksanakan proses belajar mengajar sesuai dengan langkahlangkah rencana proses pembelajaran, dimana pengelolaan kelas yang baik dari pihak guru sangat penting dalam keberhasilan pembelajaran. Aktivitas siswa pada kelas eksperimen dan kelas kontrol dapat dilihat pada Tabel 25 berikut :

Tabel 25 : Aktivitas Siswa Kelas Eksperimen

\begin{tabular}{|c|c|c|c|c|c|}
\hline \multirow{2}{*}{ Pertemuan } & \multicolumn{4}{|c|}{ Aktivitas (\%) } & \multirow{2}{*}{$\begin{array}{c}\text { Rerata } \\
(\%)\end{array}$} \\
\hline & 1 & 2 & 3 & 4 & \\
\hline I & 51,35 & 100 & 100 & 100 & 87,83 \\
\hline II & 59,46 & 100 & 100 & 100 & 89,87 \\
\hline
\end{tabular}

Berdasarkan Tabel 25 terlihat bahwa adanya peningkatan pada aktivitas 1 pada pertemuan 1 dan pertemuan 2 yaitu dari $51,35 \%$ menjadi 59,46\%. Sedangkan pada aktivitas 2, 3 dan 4 pada pertemuan I dan II hasilnya sama sebesar $100 \%$. Rerata persentase aktivitas siswa kelas eksperimen pertemuan I sebesar 87,83\%, sedangkan pada pertemuan II rerata persentasenya sebesar $89,87 \%$. 
Hal ini berbeda dengan aktivitas siswa kelas kontrol yang dapat dilihat pada Tabel 26 berikut :

Tabel 26 : Aktivitas Siswa Kelas Kontrol

\begin{tabular}{|c|c|c|c|c|}
\hline \multirow{2}{*}{ Pertemuan } & \multicolumn{3}{|c|}{ Aktivitas (\%) } & \multirow{2}{*}{$\begin{array}{c}\text { Rerata } \\
(\%)\end{array}$} \\
\cline { 2 - 4 } & $\mathbf{1}$ & $\mathbf{2}$ & $\mathbf{3}$ & \\
\hline I & 72,97 & 62,16 & 51,35 & 62,16 \\
\hline II & 70,27 & 45,95 & 54,05 & 56,76 \\
\hline
\end{tabular}

Berdasarkan hasil pengamatan Tabel 26 terlihat bahwa aktivitas 1 dan 2 pada pertemuan I dan II terdapat penurunan aktivitas pada aktivitas 1 dari pertemuan I yaitu $72,97 \%$ menjadi $70,27 \%$ pada pertemuan ke II, sedangkan pada aktivitas 2 dari pertemuan I yaitu $62,16 \%$ menjadi $45,95 \%$ berbeda dengan aktivitas 3 yang terdapat peningkatan pada pertemuan I dan II yaitu 51,35 \% menjadi 54,05\%. Rerata persentase juga mengalami penurunan pada pertemuan I kelas kontrol adalah 62,16\%, pada pertemuan ke II menjadi 56,76\%.

\section{B. Pembahasan}

Berdasarkan hasil analisis data pretest pada kelas eksperimen dan kelas kontrol yang telah diuji dengan uji statistik parametrik, yaitu Uji-t diperoleh Sig. (2tailed) adalah 0,013>0,05dengan keputusan tolak $\mathrm{H}_{0}$, yang artinya terdapat perbedaan yang signifikan antara nilai pretest kelas eksperimen dan kelas kontrol. Hal ini dapat dilihat dari rerata pretest kelas eksperimen sebesar 46,58 dan pada kelas kontrol 55,23. Pretest dilakukan untuk melihat kemampuan awal siswa, hal ini sesuai menurut Purwanto (2012), pretest yakni tes yang diberikan sebelum pengajaran dimulai, dan bertujuan untuk mengetahui sampai dimana penguasaan siswa terhadap bahan pengajaran (pengetahuan dan ketrampilan) yang akan diajarkan. Pretest pada penelitian ini menunjukkan bahwa siswa pada kelas eksperimen dan kelas kontrol memiliki pengetahuan awal yang berbeda terhadap tentang materi Pelestarian Lingkungan, dimana pada kelas eksperimen rerata pretest lebih rendah dan pada kelas kontrol rerata pretest lebih tinggi. Hal ini disebabkan karena pengambilan data pretest pada kelas eksperimen dan kelas kontrol berbeda dari segi waktu pelaksanaan tes. Pengambilan data pretest pada kelas eksperimen dilakukan pada siang hari sedangkan pengambilan data pretest kelas kontrol dilakukan pada pagi hari. Hal ini disebabkan karena konsentrasi siswa pada pagi hari lebih bagus dari pada siang hari (Sabri, 2010).

Setelah dilakukan proses pembelajaran dengan menggunakan strategi Know-WantLearn (KWL) dalam model pembelajaran SQ4R, hasil belajar siswa pada materi 
Pelestarian Lingkungan di kelas eksperimen lebih tinggi dibandingkan kelas kontrol yang hanya menggunakan metode konvensional. Hal ini dapat dilihat setelah data posttest dilakukan uji normalitas, uji homogenitas data berdistribusi normal dan homogen. Pada uji-t diperoleh nilai sig. (2-tailed) untuk data posttest kelas eksperimen dan kelas kontrol sebesar 0,030<0,05 dengan keputusan tolak $\mathrm{H}_{0}$ artinya data berbeda signifikan. Berarti siswa pada kelas eksperimen dan kelas kontrol memiliki hasil belajar yang berbeda pada materi Pelestarian Lingkungan.

Posttest adalah tes yang diberikan setelah mendapat pengajaran atau perlakuan. Dilihat dari nilai rerata posttest kelas eksperimen sebesar 76,49sedangkan kelas kontrol sebesar 71,89. Hal ini dikarenakan pada kelas kontrol menggunakan pembelajaran konvensional dimana siswa hanya mendengarkan ceramah oleh gurunya saja selama proses pembelajaran berlangsung. Pada kelas eksperimen menggunakanstrategi KWL dalam model pembelajaran SQ4R yang menggunakan bahan ajar seperti handout untuk membuat siswa mampu mengetahui apa yang diketahui, apa yang ingin di ketahui dan apa yang telah dipelajari dalam langkah-langkah menarik. Dengan begitu pembelajaran menjadi lebih menyenangkan dan siswa aktif bertanya serta tertarik dengan strategi dan model pembelajaran yang dilakukan oleh guru dalam proses belajar mengajar.

Penelitian ini mendukung penelitian Rahayu (2014), yaitu Keunggulan dari model kooperatif tipe SQ4R diantaranya adalah 1) dapat mengaktifkan pengetahuan awal siswa dan megawali proses pembuatan hubungan antara informasi baru dengan apa yang telah diketahui sebelumnya, 2) dapat membantu siswa mengingat apa yang telah dibaca atau efektif dalam membantu siswa menghafal informasi dari bacaan, 3) dapat membantu siswa memahami suatu bacaan, 4) membantu siswa untuk belajar sendiri, 5) membantu siswa untuk berpikir kritis, 6) dapat meningkatkan rasa senang dan konsentrasi siswa pada pembelajaran.

Berdasarkan hasil analisis data N-Gain pada Tabel 12 dengan menggunakan uji hipotesis komparatif yaitu uji- $t$ menunjukan bahwa tolak $\mathrm{H}_{0}$ yang artinya terdapat perbedaan yang signifikan antara kelas eksperimen dan kelas kontrol. Adapun rerata nilai N-Gain kelas eksperimen 0,57 sedangkan rerata N-Gain pada kelas kontrol 0,34.Hal ini disebabkan pada kelas eksperimen diberikan pembelajaran menggunakan strategi Know-Want-Learn (KWL) dalam model pembelajaran SQ4R 
sedangkan pada kelas kontrol diberikan pembelajaran menggunakan model konvensional.Ini berarti pembelajaran menggunakanstrategi Know-Want-Learn (KWL) dalam model pembelajaran SQ4R, yang dilakukan di kelas eksperimen lebih baik dari pada pembelajaran konvensional di kelas kontrol.

Berdasarkan hasil penelitian yang telah dilakukan pada kelas eksperimen terjadi adanya peningkatan aktivitas belajar siswa pada pertemuan 1 dan pertemuan 2 yaitu dari $51,35 \%$ menjadi $59,46 \%$, hal ini disebabkan oleh meningkatnya semangat siswa untuk bercurah pendapat tentang materi Pelestarian Lingkungan, sedangkan pada aktivitas 2, 3 dan 4 pada pertemuan I dan II hasilnya sama sebesar $100 \%$ karena pada aktivitas ini semua siswa dituntut untuk melaksanakan. Rerata persentase aktivitas siswa kelas eksperimen meningkat yaitu pada pertemuan I sebesar $87,83 \%$, sedangkan pada pertemuan II rerata persentasenya sebesar $89,87 \%$. Berbeda dengan hasil penelitian yang telah dilakukan dikelas kontrol yang mengalami penurunan Rerata persentasepada pertemuan I kelas kontrolsebesar 62,16\% menjadi 56,76\% pada pertemuan ke II. Maka dapat dikatakan bahwa aktifitas siswa pada kelas kontrol lebih rendah dibanding aktivitas siswa kelas eksperimen. Hal ini dapat disimpulkan bahwa aktivitas siswa juga mempengaruhi hasil belajar siswa.

Peningkatan hasil belajar siswa dipengaruhi aktivitas siswa selama pembelajaran diatas sesuai dengan penelitian penelitian yang dilakukan oleh Aryani (2012), bahwa penerapan strategi KWL dapat meningkatkan aktivitas siswa dalam pembelajaran keterampilan membaca pemahaman. Peningkatan dalam kemampuan membaca ini juga merperkuat penelitian Dewi (2014), yang menyatakan bahwa peningkatan kemampuan membaca intensif disebabkan oleh beberapa faktor; pertama, adalah penerapan strategi KWL dalam proses pembelajaran; Faktor kedua, pemilihan dan penggunaan media yang berkaitan dengan perkembangan zaman dan kesukaan siswa.

Rerata aktivitas guru pada kelas eksperimen pada pertemuan I 100\% dan II $100 \%$ sedangkan kelas kontrol pertemuan I $100 \%$ dan II 100\%. Maka dapat dikatakan bahwa aktivitas guru pada kelas kontrol dan kelas eksperimen persentasenya sama. Peningkatan dalam kemampuan membaca ini juga merperkuat penelitian Dewi (2014), yang menyatakan bahwa pemberian bimbingan dan penghargaan oleh guru dapat mendorong siswa menjadi lebih baik. 
Agar mendapat hasil lebih baik pada penelitian ini juga memakai model pembelajaran SQ4R yang mampu meningkatkan hasil belajar siswa melalui langkah-langkah belajar yang menarik, hal ini sesuai dengan penelitian yang dilakukan oleh Rasjid (2015), yang mengungkapkan bahwa model pembelajaran SQ4R ini terbukti efektif meningkatkan hasil belajar siswa. Langkah-langkah model pembelajaran SQ4R (survey, question, read, reflect, recite, review) adalah kegiatan membaca efektif yang pada pelaksanaannya siswa harus memahami terlebih dahulu apa yang akan dipelajari sehingga dapat dengan mudah mengingat pembelajaran lebih lama dan persentasi.

Keunggulan yang dapat diperoleh melalui model pembelajaran SQ4R menurut Ulfi dalam Rahayu (2014), diantaranya adalah 1) dapat mengaktifkan pengetahuan awal siswa dan megawali proses pembuatan hubungan antara informasi baru dengan apa yang telah diketahui sebelumnya, 2) dapat membantu siswa mengingat apa yang telah dibaca atau efektif dalam membantu siswa menghafal imformasi dari bacaan, 3) dapat membantu siswa memahami suatu bacaan, 4) membantu siswa untuk belajar sendiri, 5) membantu siswa untuk berpikir kritis, 6) dapat meningkatkan rasa senang dan konsentrasi siswa pada pembelajaran.

Selain langkah read dan tahap learn strategi dan model pada penelitian ini mempunyai perbedaan yang sangat berpengaruh seperti pada aktivitas 1 yaitu curah pendapat. Dengan guru melakukan curah pendapat terhadap siswa, maka siswa akan termotivasi untuk mengingat kembali pegetahuannya tentang materi yang terkait dan dapat terlihat sampai dimana pengetahuan siswa sehingga mempermudah guru untuk memberikan pembelajaran (Erfin, 2016). Pada aktivitas ini juga dapat meningkatkan aktivitas siswa dalam mengungkapkan pengetahuannya hal ini terbukti dari meningkatnya hasil aktivitas 1 pada pertemuan I yaitu 51,35\% menjadi $59.46 \%$ pada pertemuan II.

Berbeda halnya dengan pembelajaran secara konvensional yang disampaikan dengan menggunakan metode ceramah, dan pemberian tugas. Hal ini menunjukkan aktivitas guru lebih banyak dari pada aktivitas siswa dan siswa menjadi kurang memahami pelajaran yang akan dipelajari. Aktivitas guru pada kelas eksperimen dengan menggunakan strategi Know-WantLearn (KWL) dalam model pembelajaran SQ4R selain melihat hasil belajar siswa, juga mengamati aktivitas siswa dan guru 
dengan menggunakan lembar observasi. Hal ini bertujuan untuk melihat aktivitas siswa dan guru pada saat proses belajar mengajar berlangsung. Lembar observasi guru disesuaikan dengan pelaksanaan pembelajaran (RPP) dan dilakukan di kelas kontrol maupun kelas eksperimen.

Pada lembar observasi aktivitas guru dan siswa akan terlihat perubahan tingkah laku siswa dan guru selama pembelajaran. Dalam penggunaan strategi Know-Want-Learn (KWL) dalam model pembelajaran SQ4R siswa diarahkan untuk aktif dalam proses pembelajaran, tidak hanya sekedar mendengar, selain itu siswa juga harus mampu dalam mengkontruksi dan membangun pengetahuan baru dari membaca. Penelitian yang dilakukan oleh Aryani (2012), bahwa penerapan strategi KWL dapat meningkatkan aktivitas siswa dalam pembelajaran keterampilan membaca pemahaman.

\section{KESIMPULAN}

Berdasarkan penelitian yang telah dilakukan di SMA N 16 Pekanbaru, bahwa strategi Know-Want-Learn (KWL) dalam model pembelajaran SQ4R sebagai sumber belajar berpengaruh terhadap hasil belajar siswa pada materi pelestarian lingkungan di kelas X SMA N 16 Pekanbaru T.A 2017 /2018.
Peningkatan hasil belajar siswa dapat dilihat dari hasil N-Gain kelas eksperimen sebesar 0,57 termasuk kategori sedang dan N-Gain kelas kontrol 0,34 termasuk kategori sedang. Berdasarkan hasil observasi aktivitas siswa diperoleh rerata pada kelas kontrol pertemuan I 38,73\% dan pada pertemuan ke II yaitu 37,83 dan pada kelas eksperimen rerata aktivitas siswa pada pertemuan I yaitu $87,83 \%$ dan pada pertemuan ke II yaitu $89,87 \%$, sedangkan aktivitas guru pada kelas eksperimen pertemuan I yaitu $100 \%$ dan pertemuan ke II $100 \%$ sedangkan pada kelas kontrol aktivitas guru pada pertemuan I yaitu $100 \%$ dan pertemuan ke II yaitu $100 \%$.

\section{SARAN}

a. Diperlukan pengawasan yang ekstra bagi kelas dengan jumlah siswa yang banyak, agar siswa mengerjakan LKS dengan baik dan benar.

b. Meningkatnya hasil belajar siswa dengan strategi KWL dan model SQ4R diharapkan bisa juga diterapkan untuk materi pelajaran Biologi lainnya.

\section{DAFTAR PUSTAKA}

Arikunto, S. (2009). Dasar-Dasar Evaluasi Pendidikan. Bumi Aksara : Jakarta

Arsyad, A.(2014). Media Pembelajaran. Rajawali Pers : Jakarta 
Aryani, S., Samadhy, U., Sismulyasih, N. (2012). Peningkatan Keterampilan Membaca Pemahaman Melalui Strategi Know-Want-Learned (KWL) Pada Siswa Kelas IVa SDN Sekaran 01 Semarang. Journal of Elementary Education 1 (1) Hal : 62-70

Asrori, M. (2007). Psikologi Pendidikan. Wacana Prima : Bandung

Carr, E. \& Ogle, D. (1987). K-W-L Plus: A Strategy for Comprehension and Summarization. Journal of Reading, 30 (7), 626-631. Diperoleh 16

November 2017, dari http://eric.ed.gov/ERICWebPortal.

Darmawan, I.P.A dan Sujoko, E. (2013). Revisi Taksonomi Pembelajaran Benyamin S. Bloom. Jurnal Setya Widya, Vol. 29 No. 1 Hal : 30-39

Dewi, N.P.W.C., Sudiana, I. N., Darmayanti, I.A.M. (2014). Penerapan Strategi KWL (Know, Want Toknow, Learned) Untuk Meningkatkan Kemampuan Membaca Intensif Siswa di Kelas VII D SMP NEGERI 1 SAWAN. Jurnal Pendidikan, Vol. 2 No. $1 \mathrm{Hal}: 1-11$

Erfin. (2016). Strategi KWL Untuk Meningkatkan Kemampuan Membaca Siswa di Sekolah Dasar. Kota Tasikmalaya. Jurnal Ilmiah Guru, Vol. 20 No. 2Hal : 41-49

Fraenkel, J.R dan Wallen, N.E. (2009). How to Design and Evaluate Research in Education. McGraw-Hill Companies, Inc : New York

Hamalik, O. (2010). Kurikulum dan Pembelajaran.Bumi Aksara : Jakarta
Harsono, A.S.R., Fuady, A., Saddhono, K. (2012). Pengaruh Strategi Know Want To Learn (KWL) dan Minat Membaca Terhadap Kemampuan Membaca Intensif Siswa Smp Negeri di Temanggung. Kota Temanggung. Jurnal Penelitian Bahasa, Vol. 1 No. 1 Hal : 53-64

Hasibuan, R. (2016). Analisis dampak limbah/sampah rumah tangga terhadap pencemaran lingkungan hidup. Jurnal ilmiah, Vol. 04 No. 01 Hal : 42-52

Jatmiko, D.D.H. (2017). Perbedaan Pengaruh Model Pembelajaran Probing Prompting dan SQ4R Siswa Madrasah Aliyah. Jurnal Gammath, Vol. 2 No. 1 Hal : 162-175

Lugtyastyono. (2017). Pencemaran Lingkungan dan Daur Limbah. [online]. Tersedia https://biologiklaten.wordpress.com/ba b-11-pencemaran-dan-daur-limbah$\mathrm{x} / .[16$ November 2017]

Meltzer, D.E. (2002).The relationship between mathematics preparation and conceptuallearning gains in physics: A possible "hidden variable" in diagnosticpretest scores.American Journal of Physics, Vol. 70, No. 12

Ngalimun. (2016). Strategi dan Model Pembelajaran. Aswaja Pressindo : Banjarmasin

Purwanto, Ngalim, (2012). Prinsip-prinsip dan Teknik Evaluasi Pengajaran. Remaja Rosdakarya : Bandung

Rahayu, P.I.W., Zulaikha, S., Negara, IG.A.O. (2014). Model Pembelajaran Kooperatif Tipe SQ4R Berbasis Keterampilan Proses Berpengaruh Terhadap Hasil Belajar Ipa Siswa 
Kelas V Sd Gugus Letkol Wisnu. Jurnal Mimbar PGSD, Vol. 2 No. 1

Rasjid, Y. (2015). Pengaruh Model Pembelajaran Survey Question Read Reflect Recite Review (SQ4R) dengan Metode Talking Stick Terhadap Keterampilan Metakognisi dan Hasil Belajar Biologi Siswa SMAN 9 Makassar. Jurnal Biotek, Vol. 3 No. 1Hal : $170-183$

Sabri, A. (2010). Psikologi Pendidikan. Pedoman Ilmu Jaya : Jakarta

Slameto. (2013). Belajar dan Faktor-faktor yang Mempengaruhinya. Rineka Cipta : Jakarta

Sudjana, N. (2010). Penilaian Hasil Proses Belajar Mengajar. Ramaja Rosdakarya : Bandung

Sugiyono. (2015). Statistika untuk Penelitian. Alfabeta : Bandung

Suyatno. (2009). Menjelajah Pembelajaran Inovatif. Masmedia Buana Pustaka : Sidoarjo

Ulfi. (2010). Model Pembelajaran SQ4R. [online]. Tersedia pada http://mahasiswajenius.blogspot.com/2 012/06/metode-membaca-sq4r.html. [16 November 2017] 